УДК 616.694

ПОПУЛЯЦИОННОЕ ИССЛЕДОВАНИЕ СИМПТОМОВ АНДРОГЕНОДЕФИЦИТА

Савзиханов Р.T.

\author{
Дагестанская Государственная Медицинская Академия, \\ Республика Дагестан, Махачкала \\ 367000, Республика Дагестан, г. Махачкала, пл. Ленина,1, тел. (928)5959555 \\ Эл.почта: ruslanst@mail.ru
}

Резюме. С иелью изучения распространенности андрогенодефиџита, его связи с расстройствами мочеиспускания и эректильной дисфункции в Республике Дагестан проведено популяционное исследование 780 мужчин старше 30 лет. Для выявления дефицита андрогенов использовался «Опросник симптомов старения мужчины» (AMS - Aging Males, Symptoms), расстройств мочеиспускания - шкала I-PSS, эректильной функиии - МИЭФ. Оиенка результатов исследования проводилась по общепринятым критериям. На основании статистической обработки полученных результатов симптомы андрогенодефицита выявлены у 51,15\% мужчин в Дагестане. Наибольший вклад в развитие симптомов внесли сексуальные проблемы пациентов. Каждый 5 мужчина в популящии отмечает расстройства мочеиспускания, каждый 3 мужчина имеет нарушения эректильной функции средней и тяжелой степени тяжести и каждый 8-9 отмечает сочетание обоих расстройств.

Ключевые слова: андрогенодефицит, симптомы нижних мочевых путей, эректильная дисфункиия.

\title{
POPULATION-BASED STUDY OF SYMPTOMS OF ANDROGENIC DEFICIT
}

\section{Savzikhanov R.T.}

\section{Dagestan State Medical Academy}

\begin{abstract}
To study the prevalence of androgenic deficit, its relationship with urination disorders and erectile dysfunction in the Republic of Dagestan A pilot observational study involving 780 men over 30 years was held. For detection of deficiency of androgens Aging Males' Symptoms scale, urination - the scale of I-PSS, erectile function ICEF were used. Evaluation of the results of the studies was conducted according to generally accepted criteria. On the basis of statistical processing of the results the symptoms of androgenic deficit identified at 51, 15\% of men in Dagestan. The greatest contribution to the development of symptoms has made the sexual problems of patients. Every 5 man in the population notes the disorders of urination, every 3 man has a violation of erectile function average and severe degrees of severity and every 8-9 notes the combination of both disorders.
\end{abstract}

Key words: androgenic deficit, lower urinary tract symptoms, erectile dysfunction. 
Введение. Одна из немногих проблем, с которой сталкиваются практикующие врачи урологи, требующая междисциплинарного подхода, является проблема андрогенодефицита. Зачастую, эти пациенты «блуждают» в медицинских кабинетах терапевта, кардиолога, эндокринолога, уролога и т.д. Клинические проявления андрогенодефицита весьма разнообразны и малоспецифичны. Действительно, следует отметить появление целого разнообразия расстройств, захватывающие все стороны здоровья. У большинства мужчин на первый план начинают выходить мочеполовые расстройства (1). Для выявления симптомов андрогенодефицита в клинической практике используется большое количество всевозможных анкет и опросников. Наиболее широко используется шкала J.E.Morley и самоопросник AMS (2).

Медицина в XXI веке сделала стремительный шаг к продлению жизни мужчин, вместе с тем стало актуальным улучшение их качества жизни. По прогнозам экспертов ООН, к 2020г. количество лиц пожилого возраста будет составлять $20 \%$ от общего числа жителей планеты. С урологического подхода к улучшению качества жизни мужчин мы можем говорить тогда, когда будет сведено к минимуму число больных основными «недугами» мужчин старшего возраста: расстройствами мочеиспускания и эректильной дисфункцией. Ни один современный конгресс, конференция не обходится без изучения распространенности, диагностики, лечения или взаимосвязи этих заболеваний (3). По данным различных авторов, частота клинически выраженного возрастного андрогенного дефицита у мужчин старше 30 лет возраста варьирует от 7\% до 52\% $(4,5,6,7)$. Столь значительные отличия в показателях демонстрируют отсутствие четких диагностических критериев.

Несмотря на достаточно хорошо изученные в настоящее время вопросы этиологии, патогенеза, диагностики и лечения возрастного гипогонадизма мужчин остается множество вопросов, требующих дальнейшего изучения этой проблемы. Наибольший вклад в изучение андрогенодефицита внесли исследования зарубежных авторов, имеющих в этой отрасти лучшие достижение. Это и по- 
служило основополагающим поводом для проведения данной работы, на примере дагестанского исследования, как субъекта России.

Цель исследования. Определить распространенность симптомов андрогенодефицита в мужской популяции России на примере дагестанской популяции и наличие связи с расстройствами мочеиспускания, эректильной дисфункцией, и рядом социальных и иных признаков

Материалы и методы. В основу работы на первоначальном этапе было положено проведенное нами популяционное исследование. В исследовании приняло участие 780 мужчин в возрасте от 30 до 82 лет (средний возраст 48,3). Всем мужчинам предлагалось анонимное заполнение шкалы AMS, шкалы суммарной оценки заболеваний простаты- I-PSS, международного индекса эректильной функции - IIEF. Кроме того, анкеты были дополнены вопросами, включающими в себя возраст, образование, употребление алкоголя, курение, сопутствующие заболевания, оценку сексуальной активности, количество фрикций до наступления эякуляции, возраст начала половой жизни и максимальный эксцесс в возрасте 25-30 лет. Все респонденты были разделены на V групп: I группа (от 30 до 39 лет) составила 225 человек (28, 85\%), II группа (от 40 до 49 лет)-220 человек (28, 2\%), III группа (от 50 до 59 лет)-189 человек (24, 23\%), IV группа (от 60 до 69 лет)-107 человек $(13,72)$ и V группа (старше 70 лет)-39 человек (5\%).

Анкетирование проводилось в случайном порядке на заводах, школах, предприятиях. В исследуемую когорту не включались пациенты, находящиеся на стационарном лечении. Статистическая обработка проводилась с использованием пакета прикладных программ Statistica 6,0 и электронных таблиц Excel 2003.

Результаты и их обсуждение. В результате анализа полученных данных мы установили, что распространенность симптомов андрогенодефицита в Дагестане составила $51,15 \%$. На рисунке 1 отображена зависимость суммарного балла AMS от возраста в виде графика. Ожидаемо с возрастом увеличивается частота и интенсивность симптомов шкалы. 


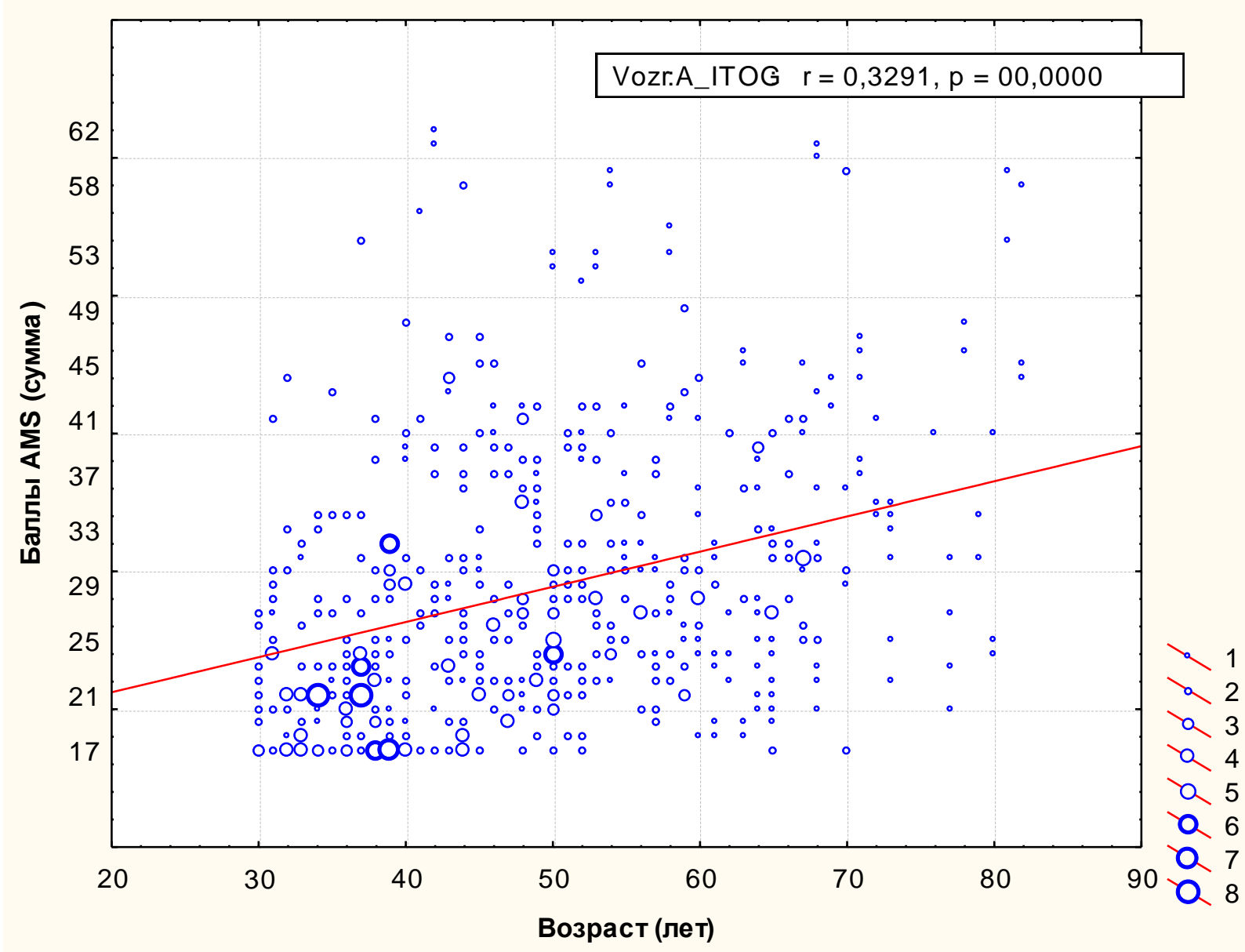

Pис 1. Зависимость от возраста суммарного балла AMS

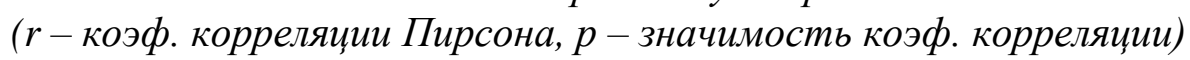

коэф. корреляции может менятся от -1 до +1 , но принимать во внимание его следует только при значении $p<0.05$

Так, если в I возрастной группе (от 30 до 39 лет) мы встретились с симптомами андрогенодефицита в 30,2 \%, то в самой возрастной, V группе, от 70 лет и старше, мы обнаружили у 79,5\% мужчин (таблица 1).

Как известно, симптомы андрогенодефицита весьма многообразны и могут включать в себя 3 крупных симптомокомплекса: психологический, соматический и сексологический. Проведенный статистический анализ позволил определить степень вклада в развитие отдельных симптомов гипогонадизма. Наибольшая частота признаков андрогенодефицита была продемонстрирована в виде сексологических симптомов, которые включают в себя: снижение способности и частоты сексуальных отношений, снижение частоты наступления утренних эрекций, снижение сексуального желания. В меньшей степени: ухуд- 
шение общего самочувствия, снижение мышечной силы, уменьшение роста бороды (таблица 2). С точки зрения специальности урологов и андрологов именно проблемы в сексуальной сфере имеют наибольшее практическое значение в проблеме андрогенодефицита у мужчин.

Таблица 1. Средние балль AMS в группах и их соотношение (N=780)

\begin{tabular}{|c|c|c|c|}
\hline Возрастные группы & $\begin{array}{c}\text { Выраженность симптомов } \\
\text { андрогенодефицита }\end{array}$ & $\begin{array}{c}\text { Средний } \\
\text { балл (AMS) }\end{array}$ & $\%$ \\
\hline \multirow{4}{*}{$\begin{array}{c}\text { 1-ая группа } \\
\text { (30-39 лет) } \\
(n=225)\end{array}$} & Не выражены (17-26 баллов) & 20,48 & 69,8 \\
\hline & Слабо выраженные (27-36 баллов) & 30,2 & 24,9 \\
\hline & Средне выраженные (37-49 баллов) & 41,4 & 4,4 \\
\hline & Резко выраженные (более 50 баллов) & 54,0 & 0,9 \\
\hline \multirow{4}{*}{$\begin{array}{c}\text { 2-ая группа } \\
\text { (40-49 лет) } \\
(n=220)\end{array}$} & Не выражены (17-26 баллов) & 21,22 & 46,8 \\
\hline & Слабо выраженные (27-36 баллов) & 30,51 & 27,73 \\
\hline & Средне выраженные (37-49 баллов) & 40,9 & 23,2 \\
\hline & Резко выраженные (более 50 баллов) & 59,0 & 2,27 \\
\hline \multirow{4}{*}{$\begin{array}{c}\text { 3-ая группа } \\
\text { (50-59 лет) } \\
(\mathrm{n}=189)\end{array}$} & Не выражены (17-26 баллов) & 22,33 & 41,8 \\
\hline & Слабо выраженные (27-36 баллов) & 29,83 & 36,5 \\
\hline & Средне выраженные (37-49 баллов) & 40,84 & 16,94 \\
\hline & Резко выраженные (более 50 баллов) & 54,11 & 4,76 \\
\hline \multirow{4}{*}{$\begin{array}{c}\text { 4-ая группа } \\
\text { (60-69 лет) } \\
(n=107)\end{array}$} & Не выражены (17-26 баллов) & 22,21 & 31,78 \\
\hline & Слабо выраженные (27-36 баллов) & 30,6 & 43,93 \\
\hline & Средне выраженные (37-49 баллов) & 41,13 & 22,42 \\
\hline & Резко выраженные (более 50 баллов) & 60,5 & 1,87 \\
\hline \multirow{4}{*}{$\begin{array}{c}\text { 5-ая группа } \\
\text { (старше } 70 \text { лет) } \\
(n=39)\end{array}$} & Не выражены (17-26 баллов) & 21,63 & 20,5 \\
\hline & Слабо выраженные (27-36 баллов) & 32,14 & 35,9 \\
\hline & Средне выраженные (37-49 баллов) & 43,0 & 30,77 \\
\hline & Резко выраженные (более 50 баллов) & 57,2 & 12,83 \\
\hline
\end{tabular}

Как известно, симптомы андрогенодефицита весьма многообразны и могут включать в себя 3 крупных симптомокомплекса: психологический, соматический и сексологический. Проведенный статистический анализ позволил определить степень вклада в развитие отдельных симптомов гипогонадизма. Наибольшая частота признаков андрогенодефицита была продемонстрирована 
Таблица 2. Величины коэффициента корреляции по Спирмену между возрастом и различными показателями, оцениваемых в AMS опроснике симптомов у мужчин

\begin{tabular}{|c|c|c|c|}
\hline & Valid & Spearman & p-level \\
\hline Депрессия & 780 & 0,028618 & 0,424787 \\
\hline Проблемы со сном & 780 & 0,051730 & 0,148909 \\
\hline Тревожность & 780 & 0,078788 & 0,027784 \\
\hline Повышенная потребность во сне, & 780 & 0,094979 & 0,007946 \\
\hline Опустошенность, & 780 & 0,105327 & 0,003229 \\
\hline Повышенная потливость & 780 & 0,122730 & 0,000592 \\
\hline Раздражительность & 780 & 0,126421 & 0,000401 \\
\hline Нервозность & 780 & 0,134009 & 0,000174 \\
\hline Физическое истощение & 780 & 0,170365 & 0,000002 \\
\hline Боли в суставах и мышечные боли & 780 & 0,208754 & 0,000000 \\
\hline Ощущение, что жизненный пик пройден & 780 & 0,236214 & 0,000000 \\
\hline Уменьшение роста бороды & 780 & 0,254902 & 0,000000 \\
\hline Ухудшение общего самочувствия & 780 & 0,266767 & 0,000000 \\
\hline Снижение мышечной силы & 780 & 0,267469 & 0,000000 \\
\hline Снижение сексуального желания & 780 & 0,348855 & 0,000000 \\
\hline $\begin{array}{c}\text { Снижение частоты наступления утренних } \\
\text { эрекций }\end{array}$ & 780 & 0,391136 & 0,000000 \\
\hline $\begin{array}{c}\text { Снижение способности и частоты } \\
\text { сексуальных отношений. }\end{array}$ & 780 & 0,486782 & 0,000000 \\
\hline Итого: & 780 & 0,350700 & 0,000000 \\
\hline
\end{tabular}

в виде сексологических симптомов, которые включают в себя: снижение способности и частоты сексуальных отношений, снижение частоты наступления утренних эрекций, снижение сексуального желания. В меньшей степени: ухудшение общего самочувствия, снижение мышечной силы, уменьшение роста бороды (таблица 2). С точки зрения специальности урологов и андрологов именно проблемы в сексуальной сфере имеют наибольшее практическое значение в проблеме андрогенодефицита у мужчин.

Андрогенодефицит по праву можно считать спутником старения мужчины. Также, безусловно, с возрастом увеличивается частота и выраженность расстройств половой функции и мочеиспускания. В связи с чем, следующим эта- 
пом нашего популяционного исследования было определение связи симптомов андрогенодефицита с симптомами нижних мочевых путей и эректильной дисфункции (таблица 3).

Таблица 3. Взаимосвязь симптомов андрогенодефицита с расстройствами мочеиспускания и эректильной дисфункиией $(N=780)$

\begin{tabular}{|c|c|c|c|c|}
\hline & AMS > 26 & $\begin{array}{l}\text { AMS > } 26 \\
+ \text { IPSS > } 7\end{array}$ & $\begin{array}{c}\text { AMS }>26 \\
+ \text { IIEF }<26\end{array}$ & $\begin{array}{r}\text { AMS }>26 \\
+ \text { IIEF }<26 \\
+ \text { IPSS }>7\end{array}$ \\
\hline $\begin{array}{c}\text { 1-ая } \\
\text { (30-39 лет) }\end{array}$ & $68(30,2 \%)$ & $7(3,1 \%)$ & $19(8,4 \%)$ & $6(2,7 \%)$ \\
\hline $\begin{array}{c}\text { 2-ая } \\
\text { (40-49 лет) }\end{array}$ & $117(53,2 \%)$ & $19(8,6 \%)$ & $37(16,8 \%)$ & $4(1,8 \%)$ \\
\hline $\begin{array}{c}\text { 3-яя } \\
\text { (50-59 лет) }\end{array}$ & $110(58,2 \%)$ & $31(16,4 \%)$ & $66(34,9 \%)$ & $19(10,1 \%)$ \\
\hline $\begin{array}{c}\text { 4-ая } \\
\text { (60-69 лет) }\end{array}$ & $73(68,2 \%)$ & $38(35,5 \%)$ & $56(52,3 \%)$ & $28(26,2 \%)$ \\
\hline $\begin{array}{c}\text { 5-ая } \\
\text { (старше } 70 \text { лет) }\end{array}$ & $31(79,5 \%)$ & $18(46,2 \%)$ & $28(71,8 \%)$ & $17(43,6 \%)$ \\
\hline Все группы & $399(51,15 \%)$ & $113(14,5 \%)$ & $206(26,4 \%)$ & $74(9,5 \%)$ \\
\hline
\end{tabular}

Итак, мужчин, имеющих совокупность симптомов андрогенодефицита и расстройства мочеиспускания, мы имели их в 14,5\% случаев всей когорты. Если в возрастной группе 30-39 лет мы встретили в 3,1\% случаев, то в группе старше 70 лет - у 46,2\% мужчин. Как видно, их количество возросло в 15 раз!

Анализ мужчин с симптомами андрогенодефицита и эректильной дисфункцией выявил их в 26,4\% случаев, причем количество их возросло с 8,4\% в I возрастной группе до 71,8\% мужчин в V возрастной группе (старше 70 лет), что может свидетельствовать о тесной связи этих симптомокомплексов.

В завершение этого этапа исследования мы проанализировали процентное соотношение в когорте исследуемых мужчин, имеющих все 3 симптомокомплекса (андрогенодефицит, расстройства мочеиспускания, эректильная дисфункция). Во всей популяционной группе мы отметили их у 9,5\% мужчин. Здесь количество мужчин возросло с 2,7\% в группе 30-39 лет до 43,6\% в группе старше 70 лет, что указывает на их увеличение практически в 20 раз! 
Анализ развития симптомов андрогенодефицита с вопросами собственной анкеты показал отсутствие связи с образованием, курением, возрастом начала половой жизни и количеством половых актов подряд в возрасте до 30 лет. В большей степени отмечена связь с самостоятельной сексуальной оценкой половой жизни мужчин. Отмечена слабая связь с употреблением алкоголя. Проведение анализа связи симптомов андрогенодефицита с хроническими заболеваниями было затруднено в связи с малым количеством таких пациентов и отсутствием поставленной цели.

Полученный статистический материал позволил нам провести изучения дополнительных корреляций. Если еще 15-20 лет назад связь эректильной дисфункции с нарушенным мочеиспусканием широко обсуждалась и предполагалась, то в настоящее время связь неоспорима. Набранный статистический материал позволил нам провести анализ распространенности эректильной дисфункции, симптомов нижних мочевых путей, а также их соотношение между собой (таблица 4).

Таблица 4. Соотношение расстройств мочеиспускания с эректильной дисфункцией в группах

\begin{tabular}{|c|c|c|c|c|c|c|}
\hline & $\begin{array}{c}\mathbf{1 - а я ~} \\
(\mathbf{3 0 - 3 9} \text { лет) }\end{array}$ & $\begin{array}{c}\mathbf{2 - а я ~} \\
(\mathbf{4 0 - 4 9} \text { лет) }\end{array}$ & $\begin{array}{c}\mathbf{3 - я я} \\
(\mathbf{5 0 - 5 9} \text { лет) }\end{array}$ & $\begin{array}{c}\mathbf{4 - а я ~} \\
(\mathbf{6 0 - 6 9} \text { лет) }\end{array}$ & $\begin{array}{c}\mathbf{5 - а я ~} \\
\text { (старше } \\
\mathbf{7 0} \text { лет) }\end{array}$ & $\begin{array}{c}\text { Все } \\
\text { группы }\end{array}$ \\
\hline IPSS > 7 & $\begin{array}{c}\text { 6 чел. } \\
(2,7 \%)\end{array}$ & $\begin{array}{c}10 \text { чел. } \\
(4,5 \%)\end{array}$ & $\begin{array}{c}22 \text { чел. } \\
(11,6 \%)\end{array}$ & $\begin{array}{c}36 \text { чел. } \\
(33,6 \%)\end{array}$ & $\begin{array}{c}19 \text { чел. } \\
(48,7 \%)\end{array}$ & $\begin{array}{c}93 \text { чел. } \\
(11,9 \%)\end{array}$ \\
\hline
\end{tabular}

В целом, во всей когорте, 780 респондентов, средний балл составил 24,9.

Из них ЭД отсутствует у 483 респондентов, составляет 61,92\% от общего количества респондентов.

ЭД лёгкой степени тяжести у 233 респондента, составляет 29,87\% от общего количества респондентов.

ЭД средней степени тяжести у 26 респондентов, составляет 3,33\% от общего количества респондентов.

ЭД тяжёлой степени у 38 респондента, составляет 4,88\% от общего количества респондентов. 
В таблице 5 показана значимость эректильной функции для различных возрастных групп. Как видно, различия между всеми возрастными группами являются высокозначимыми $(\mathrm{p}<0,001)$.

Таблица 5. Значимость различий показателей для различных возрастных групп

\begin{tabular}{|l|c|c|c|c|c|c|c|c|c|c|}
\hline & $\mathbf{p 1 - 2}$ & $\mathbf{p 1 - 3}$ & $\mathbf{p 1 - 4}$ & $\mathbf{p 1 - 5}$ & $\mathbf{p 2 - 3}$ & $\mathbf{p 2 - 4}$ & $\mathbf{p 2 - 5}$ & $\mathbf{p 3 - 4}$ & $\mathbf{p 3 - 5}$ & $\mathbf{p 4 - 5}$ \\
\hline $\begin{array}{l}\text { Эрект. } \\
\text { функ. }\end{array}$ & 0,00004 & 0,00000 & 0,00000 & 0,00000 & 0,00000 & 0,00000 & 0,00000 & 0,00000 & 0,00000 & 0,00004 \\
\hline
\end{tabular}

\section{Условные обозначения:}

p1-2 - значимость различий между 1 и 2 возрастной группами, p1-3 - значимость различий между 1 и 3 возрастной группами ... и т.д.

Итак, во всей когорте исследуемых, мы встретились с эректильной дисфункцией различной степени тяжести у 38,1\% мужчин. Причем, если в самой молодой возрастной группе 30-39 лет мы встретились у 16,9 \%, то в самой старшей группе (старше 70 лет) у 92,3\% мужчин. Все пациенты с эректильной дисфункции были разделены по степени тяжести нарушений. Так вот, большую часть их составили мужчины с нарушениями легкой степени тяжести 78,5\%, эректильную дисфункцию тяжелой степени тяжести мы встретили больше, чем средней степени, соответственно у 12,8\% и 8,8\%. Корреляционный анализ показал, что различия между всеми возрастными группами являются высокозначимыми $(\mathrm{p}<0.001)$.

Как известно международный индекс эректильной функции позволяет определить не только отклонения эректильной функции, а также удовлетворенность сексуальной жизнью, оргазмическую функцию, сексуальное желание и общую удовлетворенность. В связи с этим, было проведено изучение корреляционных связей эректильной функции с другими показателями шкалы IIEF между изучаемыми параметрами (Таблица 6). Как выяснилось, все изучаемые показатели достаточно тесно связаны между собой. Наибольшая связь эректильной функции отмечена с удовлетворенностью сексуальной жизнью (коэффициент Спирмена 0,68), в меньшей степени оргазмическая функция и либидо (коэффициент Спирмена соответственно 0,62 и о,61). 
Таблица 6. Корреляционная связь эректильной функции с другими показателями шкаль IIЕF

\begin{tabular}{|l|c|c|c|}
\hline & Valid & Spearman & p-level \\
\hline ЭРЕКТ. ФУНК. \& УДОВЛ. СЕКС. ЖИЗНЬЮ & 780 & 0,676147 & 0,00 \\
\hline ЭРЕКТ. ФУНК. \& ОРГАЗМ. ФУНКЦИЯ & 780 & 0,615474 & 0,00 \\
\hline ЭРЕКТ. ФУНК. \& СЕКСУАЛЬ. ЖЕЛАНИЕ & 780 & 0,609515 & 0,00 \\
\hline ЭРЕКТ. ФУНК. \& ОБЩАЯ УДОВЛЕТВОР. & 780 & 0,566409 & 0,00 \\
\hline
\end{tabular}

В проведенном когортном исследовании с симптомами нижних мочевых путей различной умеренной и выраженной степени тяжести мы встретились в 22,4\% случаев. Причем, если в I возрастной группе их 9,8\%, то число это возрастает до 51,3\% в V возрастной группе. Во всей когорте исследуемых мужчин с легкими симптомами расстройств мочеиспускания было 77,56\%, с умеренными и тяжелыми симптомами мы встретились в 19,23\% и 3,2\% случаев соответственно.

Таблица 7

\begin{tabular}{|c|c|c|c|c|}
\hline $\begin{array}{c}\text { Возрастные } \\
\text { группы }\end{array}$ & Выраженность симптомов & $\begin{array}{c}\text { Средний } \\
\text { балл }\end{array}$ & $\%$ & $\begin{array}{c}\text { Индекс } \\
\text { качества } \\
\text { жизни L }\end{array}$ \\
\hline \multirow{3}{*}{$\begin{array}{l}\text { 1-я группа } \\
\text { (30-39 лет) }\end{array}$} & Легкие симптомы (0-7 баллов) & 1,59 & 90,22 & \multirow{3}{*}{0,98} \\
\hline & Умеренные симптомы (8-19 баллов) & 11,19 & 9,33 & \\
\hline & Выраженные симптомы (20-35 баллов) & 25,0 & 0,44 & \\
\hline \multirow{3}{*}{$\begin{array}{l}\text { 2-я группа } \\
\text { (40-49 лет) }\end{array}$} & Легкие симптомы (0-7 баллов) & 2,23 & 82,73 & \multirow{3}{*}{1,53} \\
\hline & Умеренные симптомы (8-19 баллов) & 11,47 & 15,45 & \\
\hline & Выраженные симптомы (20-35 баллов) & 21,25 & 1,82 & \\
\hline \multirow{3}{*}{$\begin{array}{l}\text { 3-я группа } \\
\text { (50-59 лет) }\end{array}$} & Легкие симптомы (0-7 баллов) & 2,95 & 77,24 & \multirow{3}{*}{1,79} \\
\hline & Умеренные симптомы (8-19 баллов) & 13,33 & 17,46 & \\
\hline & Выраженные симптомы (20-35 баллов) & 22,3 & 5,3 & \\
\hline \multirow{3}{*}{$\begin{array}{l}\text { 4-я группа } \\
\text { (60-70 лет) }\end{array}$} & Легкие симптомы (0-7 баллов) & 3,35 & 51,4 & \multirow{3}{*}{1,86} \\
\hline & Умеренные симптомы (8-19 баллов) & 11,51 & 40,18 & \\
\hline & Выраженные симптомы (20-35 баллов) & 20,89 & 8,42 & \\
\hline \multirow{3}{*}{$\begin{array}{c}\text { 5-я группа } \\
\text { (старше } 70 \\
\text { лет) }\end{array}$} & Легкие симптомы (0-7 баллов) & 4,53 & 48,72 & \multirow{3}{*}{2,18} \\
\hline & Умеренные симптомы (8-19 баллов) & 12,74 & 48,72 & \\
\hline & Выраженные симптомы (20-35 баллов) & 23,0 & 2,56 & \\
\hline Все группы & Легкие симптомы (0-7 баллов) & 2,36 & $\mathbf{7 7 , 5 6}$ & 1,51 \\
\hline
\end{tabular}


Следующей задачей, поставленной нами, было определение вклада в развитие симптомов отдельных вопросов шкалы суммарной оценки заболеваний простаты (I-PSS). Проведенный статистический анализ позволил установить, что наибольший вклад в величину баллов I-PSS, вносят вопросы шкалы №5 (В течение последнего месяца как часто Вы ощущали слабый напор струи мочи?) и №7 (В течение последнего месяца часто Вам приходилось вставать ночью, что бы помочиться?). Соответственно в самой меньшей степени имели отношение вопросы №3 (В течение последнего месяца как часто мочеиспускание было с перерывами?) и №6 (В течение последнего месяца часто Вам приходилось прилагать усилия, чтобы начать мочеиспускание?) (Таблица 8).

Таблица 8. Симптомы мочеиспускания в зависимости от возраста

\begin{tabular}{|c|c|c|}
\hline & Коэфф. корреляции & p-level \\
\hline В1 \& Vozr & 0,288241 & 0,000000 \\
\hline В2 \& Vozr & 0,245229 & 0,000000 \\
\hline B3 \& Vozr & $\mathbf{0 , 1 2 8 1 2 3}$ & $\mathbf{0 , 0 0 0 3 3 4}$ \\
\hline B4 \& Vozr & 0,266151 & 0,000000 \\
\hline B5 \& Vozr & $\mathbf{0 , 3 5 3 0 7 5}$ & $\mathbf{0 , 0 0 0 0 0 0}$ \\
\hline B6 \& Vozr & $\mathbf{0 , 1 4 3 3 3 8}$ & $\mathbf{0 , 0 0 0 0 5 9}$ \\
\hline В7 \& Vozr & $\mathbf{0 , 3 3 9 0 8 2}$ & $\mathbf{0 , 0 0 0 0 0 0}$ \\
\hline B_ITOG \& Vozr & 0,392203 & 0,000000 \\
\hline
\end{tabular}

Вполне ожидаемо отмечена тесная корреляционная связь величины балла IPSS с индексом качества жизни $(\mathrm{r}=0,67)$ и возрастными группами $(\mathrm{r}=0,40)$. B меньшей степени отмечена связь расстройств мочеиспускания с эректильной функцией $(\mathrm{r}=-0,25)$, удовлетворенностью сексуальной жизнью $(\mathrm{r}=-0,23)$ и оргазмической функцией $(\mathrm{r}=-0,23)$. В свою очередь не отмечено связи симптомов нижних мочевых путей с курением, уровнем образования, возрастом начала половой жизни и максимальным эксцессом в возрасте до 30 лет (Таблица 9).

Совокупность симптомов нижних мочевых путей и эректильной дисфункции, выявлена в 11,9\% случаев. Причем, в первой возрастной группе (30-39 лет) мы встретили всего 6 случаев, что составило 2,7\%, а в возрастной группе стар- 
ше 70 лет - 48,7\%. Как видно, в возрасте старше 70 лет их количество возрастает почти в 20 раз и практически каждый второй мужчина страдает обоими состояниями одновременно. Статистический анализ подтвердил эти данные, и в первой и во второй возрастной группе практически не выявил связей этих симптомокомплексов. Связь начинает прослеживаться в III, IV и V возрастной группах, то есть у мужчин старше 50 лет.

Таблица 9. Величины коэффициента корреляции по Спирмену между величиной Международная система суммарной оченки заболеваний простаты в баллах (I-PSS) у мужчин и другими показателями

\begin{tabular}{|c|c|c|c|}
\hline & Valid & Spearman, $\mathbf{r}$ & p-level \\
\hline СУММ. БАЛЛ IPSS \& АНДР. ДЕФИЦИЦИТ & 780 & 0,256618 & 0,000000 \\
\hline $\begin{array}{l}\text { СУММ. БАЛЛ IPSS \&ИНДЕКС } \\
\text { КАЧЕСТВА ЖИЗНИ }\end{array}$ & 780 & 0,675047 & 0,000000 \\
\hline СУММ. БАЛЛ IPSS \&ЭРЕКТ. ФУНКЦИЯ & 780 & $-0,259097$ & 0,000000 \\
\hline СУММ. БАЛЛ IPSS \& УДОВЛ. СЕКС. ЖИЗНЬЮ & 780 & $-0,233245$ & 0,000000 \\
\hline СУММ. БАЛЛ IPSS \& ОРГАЗМ. ФУНКЦИЯ & 780 & $-0,239564$ & 0,000000 \\
\hline СУММ. БАЛЛ IPSS \& СЕКСУАЛЬ. ЖЕЛАНИЕ & 780 & $-0,191442$ & 0,000000 \\
\hline $\begin{array}{l}\text { СУММ. БАЛЛ IPSS \& ОБЩАЯ } \\
\text { УДОВЛЕТВОРЕННОСТЬ }\end{array}$ & 780 & $-0,217252$ & 0,000000 \\
\hline СУММ. БАЛЛ IPSS \& ОБРАЗОВАНИЕ & 780 & $-0,033193$ & 0,354557 \\
\hline СУММ. БАЛЛ IPSS \& УПОТР. АЛКОГОГОЛЯ & 780 & $-0,155755$ & 0,000012 \\
\hline СУММ. БАЛЛ IPSS \& КУРЕНИЕ & 780 & $-0,015776$ & 0,659992 \\
\hline СУММ. БАЛЛ ІPSS \& СЕКС. АКТИВНОСТЬ & 780 & 0,161776 & 0,000006 \\
\hline $\begin{array}{l}\text { СУММ. БАЛЛ IPSS \& КОЛИЧ. ФРИКЦИЙ } \\
\text { ДО ЭЯКУЛЯЦИИ }\end{array}$ & 780 & $-0,074041$ & 0,038698 \\
\hline $\begin{array}{l}\text { СУММ. БАЛЛ IPSS \& ВОЗР. НАЧАЛА } \\
\text { ПОЛОВОЙ ЖИЗНИ }\end{array}$ & 780 & 0,044316 & 0,216342 \\
\hline $\begin{array}{l}\text { СУММ. БАЛЛ IPSS \& МАКС. КОЛ. } \\
\text { ПОЛОВ. АКТОВ ПОДРЯД }\end{array}$ & 780 & $-0,023127$ & 0,518965 \\
\hline СУММ. БАЛЛ IPSS \& ВОЗР. ГРУППЫ & 780 & 0,404846 & 0,000000 \\
\hline
\end{tabular}

Подводя итог результатов исследования, мы убедились в актуальности проблемы андрогенодефицита. Ее распространенность, тесная связь с эректильной дисфункцией, симптомами нижних мочевых путей диктует необходимость в поиске новых и современных методов диагностике и лечения. 
Таблица 10. Соотношение расстройств мочеиспускания с эректильной дисфункиией в группах

\begin{tabular}{|c|c|c|c|c|c|c|}
\hline & $\begin{array}{c}\text { 1-ая } \\
\text { (30-39 } \\
\text { лет) }\end{array}$ & $\begin{array}{c}\text { 2-ая } \\
(40-49 \\
\text { лет) }\end{array}$ & $\begin{array}{c}\text { 3-яя } \\
(50-59 \\
\text { лет) }\end{array}$ & $\begin{array}{c}\text { 4-ая } \\
\text { (60-69 } \\
\text { лет) }\end{array}$ & $\begin{array}{c}\text { 5-ая } \\
\text { (старше } \\
70 \text { лет) }\end{array}$ & Все группы \\
\hline $\begin{array}{c}\text { IPSS }>7 \\
+ \text { IIEF }<26\end{array}$ & $\begin{array}{c}6 \text { чел. } \\
(2,7 \%)\end{array}$ & $\begin{array}{l}10 \text { чел. } \\
(4,5 \%)\end{array}$ & $\begin{array}{l}22 \text { чел. } \\
(11,6 \%)\end{array}$ & $\begin{array}{l}36 \text { чел. } \\
(33,6 \%)\end{array}$ & $\begin{array}{l}19 \text { чел. } \\
(48,7 \%)\end{array}$ & 93 чел. $(11,9 \%)$ \\
\hline
\end{tabular}

Выводы. К сожалению, на практике мы часто видим, что врачами недооценена важность применения опросников и шкал, которых у современного врача в арсенале достаточно. Дополнительно может быть использована собственная анкета, упрощающая сбор анамнеза. Она позволяет пациентам внимательно и вдумчиво разобраться в своих жалобах и дать наиболее точный ответ.

1. Опросник AMS является важным источником информации для исследователей с целью выявления симптомов андрогенодефицита, так как понятен и интересен для респондентов. Результаты анкеты позволяют определять и, что очень важно, качественно оценивать результаты терапии. Следовательно, его необходимо использовать как для диагностики, так и для оценки динамики симптомов и качества проводимой терапии. Наибольшие затруднения у респондентов возникали с заполнением шкалы IIEF.

2. Распространенность симптомов андрогенодефицита у мужчин в Дагестане старше 30 лет составляет 51,15\%. Выраженность симптомов андрогенодефицита тесно коррелирует с возрастом, бо́льшая тяжесть симптомов характерна для мужчин старше 50 лет. Наибольший вклад в развитие симптомов андрогенодефицита вносят нарушения в половой сфере мужчин. Не определена связь симптомов андрогенодефицита с образованием, вредными привычками, сексуальным анамнезом.

3. Корреляционный анализ установил достоверные прямые связи между симптомами андрогенодефицита, симптомами нижних мочевых путей и эректильной дисфункцией. Каждый 5 мужчина в популяции отмечает расстройства мочеиспускания, каждый 3 мужчина имеет нарушения эректильной функции 
средней и тяжелой степени тяжести и каждый 8-9 отмечает сочетание обоих расстройств.

\section{Литература}

1. Каррузерс, М. Революция тестостерона / М. Каррузерс, - М.: МЕДПРАКТИКА-М, 2005. - 224c.

2. Калинченко, С.Ю. Практическая андрология / С.Ю. Калинченко, И.А. Тюзиков. - М.: Практическая медицина,2009. - 399с.

3. Коган, М. И. Соотношение и взаимосвязь эректильной функции и нарушений мочеиспускания в мужской популяции Дагестана. / Коган М. И., Савзиханов Р.Т. // Материалы российской научной конференции с международным участием «Фундаментальные исследования в уронефрологии». - Саратов: Издательство СГМУ, 2009.- С. 480-481.

4. Верткин, А.Л. Приобретенный возрастной дефицит андрогенов / А.Л. Верткин, С.Ю. Калинченко // Медицинская газета. - 2006.-№17. - стр. 2-3.

5. Kaufman, J.M. Declining gonadal function in elderly men / J.M. Kaufman, A. Vermeulen // BaillieresClinEndocrinolMetab. - 1997. - Vol. 11. - P. 289-309.

6. Bagatell, C.J Drug therapy: androgens in men - uses and abuses / C.J. Bagatell, W.J. Bremner // N Engl J Med. - 1996. - Vol.334. - P.707 - 714.

7. Jockenhovel, F. Male hypogonadism. - Bremen: UNI-MED Vergal , 2004. 